\title{
Metagenomic insights into bioaugmentation and biovalorization of oily industrial wastes by lipolytic oleaginous yeast yarrowia lipolytica during successive-batch fermentation
}

Louhasakul, Yasmi; Cheirsilp, Benjamas; Treu, Laura; Kougias, Panagiotis ; Angelidaki, Irini

\section{Published in:}

Biotechnology and Applied Biochemistry

Link to article, DOI:

10.1002/bab.1878

Publication date:

2021

Document Version

Peer reviewed version

Link back to DTU Orbit

Citation (APA):

Louhasakul, Y., Cheirsilp, B., Treu, L., Kougias, P., \& Angelidaki, I. (2021). Metagenomic insights into bioaugmentation and biovalorization of oily industrial wastes by lipolytic oleaginous yeast yarrowia lipolytica during successive-batch fermentation. Biotechnology and Applied Biochemistry, 67(6), 1020-1029. https://doi.org/10.1002/bab.1878

\section{General rights}

Copyright and moral rights for the publications made accessible in the public portal are retained by the authors and/or other copyright owners and it is a condition of accessing publications that users recognise and abide by the legal requirements associated with these rights.

- Users may download and print one copy of any publication from the public portal for the purpose of private study or research.

- You may not further distribute the material or use it for any profit-making activity or commercial gain

- You may freely distribute the URL identifying the publication in the public portal 
Metagenomic Insights into Bioaugmentation and Biovalorization of Oily Industrial Wastes by Lipolytic Oleaginous Yeast Yarrowia lipolytica during Successive-batch Fermentation

Yasmi Louhasakul ${ }^{\mathrm{a}}$, Benjamas Cheirsilp ${ }^{\mathrm{a},{ }^{*}}$, Laura Treu ${ }^{\mathrm{b}}$, Panagiotis G. Kougias ${ }^{\mathrm{b}, \mathrm{c}}$ and Irini Angelidaki ${ }^{\mathrm{b}, *}$

${ }^{a}$ Biotechnology for Bioresource Utilization Laboratory, Department of Industrial Biotechnology,

Faculty of Agro-Industry, Prince of Songkla University, Hat-Yai, 90112, Thailand

${ }^{b}$ Department of Environmental Engineering, Technical University of Denmark, Kgs. Lyngby 2800,

Denmark

${ }^{c}$ Hellenic Agricultural Organization, Soil and Water Resources Institute, Thermi, Thessaloniki, 57001,

Greece

*Corresponding author:

${ }^{1}$ Benjamas Cheirsilp

Tel: +66-7428-6374

E-mail: benjamas.che@psu.ac.th

This article has been accepted for publication and undergone full peer review but has not been through the copyediting, typesetting, pagination and proofreading process, which may lead to differences between this version and the Version of Record. Please cite this article as doi: $\underline{10.1002 / b a b .1878 .}$.

This article is protected by copyright. All rights reserved. 
${ }^{2}$ Irini Angelidaki

Tel: +45 251600

E-mail: iria@env.dtu.dk

Acronyms

ANOVA : Analysis of Variance

B1-B5 : $1^{\text {st }}-5^{\text {th }}$ Batch

CG : Crude Glycerol

COD : Chemical Oxygen Demand

FAME : Fatty Acid Methyl Ester

ITS : Internal Transcribed Spacers

OTU : Operational Taxonomy Unit

PCR-DGGE : Polymerase Chain Reaction-Denaturing Gradient Gel Electrophoresis

POME: Palm Oil Mill Effluent

TN : Total Nitrogen

YPD: Yeast extract Peptone Dextrose

This article is protected by copyright. All rights reserved. 


\begin{abstract}
The lipolytic oleaginous yeast Yarrowia lipolytica was used in the bioaugmentation and biovalorization of oily industrial wastes during successive-batch fermentation. Five cycles of nonsterile successive-batch fermentation with $70 \%$ medium replacement achieved the highest oil removal of $68.1 \pm 5.60 \%$ and produced biomass and lipid yields of $0.213 \pm 0.07 \mathrm{~g} / \mathrm{g}-\mathrm{COD}$ and $146.2 \pm 46.5 \mathrm{mg} / \mathrm{g}-\mathrm{COD}$, respectively. The cell-bound lipase activity observed in the system was $170.74 \pm 32 \mathrm{U} / \mathrm{L}$. The auto-flocculation efficiency of the biomass was $>90 \%$ within $60 \mathrm{~min}$. The microbial community changes between $Y$. lipolytica and indigenous microorganisms were monitored by metagenomic next-generation sequencing of internal transcribed spacer rDNA regions for yeasts and $16 \mathrm{~S}$ rRNA gene for bacteria. Y. lipolytica was retained in the consortium together with other indigenous strains until the fifth cycle. Other minor oleaginous yeasts such as Kodamaea ohmeri and Candida tropicalis as well as polyhydroxyalkanoate-accumulating bacteria were found and are likely to have participated in lipid production. This study has shown the robustness of $Y$. lipolytica in nonsterile successive-batch fermentation and its use could contribute greatly to the practical valorization of industrial wastes for lipids and lipases.
\end{abstract}

Keywords: Cell-bound lipase; industrial wastes; lipids; next-generation sequencing; successive-batch fermentation

This article is protected by copyright. All rights reserved. 


\section{Introduction}

Bioaugmentation is the addition of microorganisms to speed up the degradation rate of contaminants and pollutants (1). Yarrowia lipolytica TISTR 5151 has been previously reported as a promising yeast for the biovalorization of industrial wastes to produce lipids and lipases (2). The further development of its cultivation using non-sterile industrial wastes will boost its potential use and contribute to the effective bioaugmentation and biovalorization of industrial wastes. The cultivation of microbial cultures in non-sterile condition is more practical than in sterile condition, especially when the high cost for sterilization is considered $(3,4)$

Microbial lipids produced by oleaginous microorganisms have been considered as a good alternative biodiesel feedstock due to their fatty acid compositions similar to those of plant oils $(5,6)$. Simultaneous lipid production and wastewater treatments using oleaginous yeasts have been studied $(7,8)$. In addition to lipids, some specific yeasts are able to produce extracellular and cellbound lipases which have high potential as biocatalysts for biodiesel production (9). Compared to extracellular lipases, these cell-bound lipases are more attractive because they can be directly applied as immobilized biocatalysts after cultivation, without purification and immobilization steps.

However, in order to achieve a stable process for target products, it is necessary to ensure that the vital microorganisms are retained and possibly predominate in the consortium under nonsterile conditions. Since the presence of indigenous microorganisms would be inevitable in a nonsterile system, determination of the growth of target microorganisms and contaminants is necessary. The most common method practiced for microbe identification is plate counting. However, the major limitation of the plate-counting technique is associated with the fact that a large proportion of the microorganisms in any environment are uncultivable and unidentifiable (10). This article is protected by copyright. All rights reserved. 
To overcome the problems associated with culture-dependent methods, molecular techniques have been developed which highlight the huge underestimation of the true microbial diversity in natural and engineered environments $(11,12)$.

Early molecular biology techniques for microbial diversity analysis such as polymerase chain reaction-denaturing gradient gel electrophoresis (PCR-DGGE) can only identify the most abundant microorganisms (13). With the recently developed metagenomic next-generation sequencing of $16 \mathrm{~S}$ rRNA gene, it is possible to define the composition of a microbial community with a higher sequencing depth (14). Production performance in a non-sterile system is directly associated with different communities of microorganisms and 16S rRNA gene is highly effective in bacteria/archaea identification; however, it is not specific in yeast/fungal identification. Therefore, the internal transcribed spacers (ITS) have been applied as critical marker which provides high-level resolution among yeast/fungal members (15).

Successive-batch fermentation, also called repeated-batch culture, has been applied for the cultivation of many microorganisms because it extends the production phase by replacing a large portion of the culture with fresh medium. This mode requires less time for the seed preparation, inoculation, cleaning and sterilization steps during the fermentation process and also improves the overall productivity (16). The aim of this study was to evaluate and optimize the successive-batch fermentation of industrial wastes derived from palm oil mills by Y. lipolytica TISTR 5151 for the production of lipids and cell-bound lipase, which could be alternative sources of biodiesel feedstocks and biocatalysts, respectively. Different levels of medium replacement (i.e. $50 \%, 70 \%$ and $90 \%$ ) and performance using sterile and non-sterile industrial wastes were evaluated. During the experiment, the composition of the microbial community was monitored. More specifically, 
next-generation sequencing of $16 \mathrm{~S}$ rRNA gene V4 region and ITS region were used to identify the bacterial/archaeal populations and yeast population, respectively.

\section{Materials and Methods}

\section{Microorganisms and media}

The oleaginous yeast, Yarrowia lipolytica TISTR 5151, obtained from the Thailand Institute of Scientific and Technological Research, was used for the production of lipids and lipase in this study. Yeast extract peptone dextrose (YPD) medium (pH 6.0), with addition of glucose $40(\mathrm{~g} / \mathrm{L})$ and peptone $5(\mathrm{~g} / \mathrm{L})$ and yeast extract $15(\mathrm{~g} / \mathrm{L})$, was used to prepare the yeast inoculum. The industrial wastes used in this study were palm oil mill effluent (POME) added with $2 \%$ crude glycerol (CG). POME was taken from a primary pond of palm oil mill (Surat Thani, Thailand) and CG was obtained from the biodiesel plant at Faculty of Engineering (Prince of Songkla University, Thailand). Before use, POME was centrifuged at $6,000 \mathrm{rpm}$ for $30 \mathrm{~min}$ to remove suspended solids and stored at -20 oC, in $1 \mathrm{~L}$ bottles, while CG was evaporated at 80 ㅇ $\mathrm{C}$ for $1 \mathrm{~h}$ to remove the residual methanol and then stored at $4 \stackrel{\circ}{ } \mathrm{C}$, in $1 \mathrm{~L}$ bottles. The industrial wastes contained chemical oxygen demand (COD) of $101 \pm 10 \mathrm{~g} / \mathrm{L}$, total nitrogen $(\mathrm{TN})$ of $1.2 \pm 0.2 \mathrm{~g} / \mathrm{L}$, oil and grease of $3.3 \pm 0.4 \mathrm{~g} / \mathrm{L}$, glycerol concentration of $12.4 \pm 1.7 \mathrm{~g} / \mathrm{L}$ and $\mathrm{pH}$ of $5.95 \pm 0.07$. These characteristics were in the range of those previously reported $(2,17,22)$.

This article is protected by copyright. All rights reserved. 


\section{Successive-batch fermentation}

The yeast inoculum was incubated in YPD medium at room temperature $\left(30 \pm 2^{\circ} \mathrm{C}\right)$ for $18-24$

h. The yeast culture was inoculated into $50 \mathrm{~mL}$ of YPD medium in $250 \mathrm{~mL}$ Erlenmeyer flasks and incubated at room temperature $\left(30 \pm 2^{\circ} \mathrm{C}\right)$ and $140 \mathrm{rpm}$ for $24 \mathrm{~h}$ before use as a seed culture. Thereafter, batch fermentation was performed by inoculating $10 \mathrm{~mL}$ of seed culture $\left(10^{7}\right.$ cells $/ \mathrm{mL}$ ) into $250 \mathrm{~mL}$ Erlenmeyer flasks containing $90 \mathrm{~mL}$ of autoclaved-sterile industrial wastes. The initial $\mathrm{pH}$ was adjusted to 6.0 . The incubation was performed at room temperature $\left(30 \pm 2^{\circ} \mathrm{C}\right)$ with shaking speed at $140 \mathrm{rpm}$ for $72 \mathrm{~h}(17)$. The samples were taken every $12 \mathrm{~h}$ and centrifuged at $1,585 \times \mathrm{g}$ for 15 $\min$ to separate the cells from the supernatant. The biomass, lipid production, cell-bound lipase activity, flocculation efficiency, COD removal, glycerol removal, oil removal and pH were determined. At the end of each cycle, the culture broth was withdrawn and replaced by an equal volume of fresh medium to initiate a new cycle without new inoculation. Three fractions of medium replacement corresponding to $50 \%, 70 \%$ and $90 \%$ of the total volume were applied and each fraction was repeated every $72 \mathrm{~h}$ for 5 cycles. Successive-batch fermentations using non-sterile wastes inoculated with and without yeast were performed at suitable medium replacement.

\section{DNA extraction and sequence analysis}

Samples $(8-10 \mathrm{~mL})$ were taken from the shaken-flask at the end of each cycle of successive-batch fermentation, transferred to $15 \mathrm{~mL}$ Falcon Conical Centrifuge tubes and subsequently centrifuged at $13,500 \mathrm{rpm}$ for $10 \mathrm{~min}$. The supernatant was discarded and the remaining pellet $(\sim 0.25 \mathrm{~g}-0.4 \mathrm{~g})$ was used for DNA extraction. Total DNA was extracted using the PowerSoil ${ }^{\circledR}$ DNA Isolation Kit (MO BIO laboratories, Inc.) according to the protocol provided by the manufacturer. An extra purification step using Phenol: Chloroform: Iso-amyl alcohol (24:24:1 This article is protected by copyright. All rights reserved. 
$(\mathrm{v} / \mathrm{v} / \mathrm{v}), \mathrm{pH} 8)$ was added to improve the final quality of the extracted samples. Total DNA quality and quantity were determined using NanoDrop (Thermo Fisher Scientific, Waltham, MA). The hyper variable V4 region of bacterial $16 \mathrm{~S}$ rRNA genes was amplified using the primers $515 f\left(5^{\prime}\right.$ GTGCCAGCMGCCGCGGTAA-3') and 806r (5'- GGACTACHVGGGTWTCTAAT-3'). The ITS region of yeast rRNA genes was amplified using the primers ITS1F (5'-

ACACTGTCCGGCTTCGCTTGGTCATTTAGAGGAAGTAA- 3') and ITS4 (5'-

GTCCGTCCGGATCCTCCGCTTATTGATATGC- 3'). The DNA samples were sequenced on the MiSeq platform (Illumina). Library preparation, quality controls and sequencing were performed at the Ramaciotti Centre for Genomics (Sydney, Australia). The sequencing data were analyzed by CLC Workbench software (v8.0.2) with the Microbial Genomics Module (QIAGEN Bioinformatics, Germany). Raw reads were trimmed to remove adaptors and chimera fragments including nonspecified DNA fragments and quality filtered. Then overlapped paired-ends were merged, clustered into operational taxonomic units (OTUs) and taxonomically assigned using the databases, UNITE (v7.2) and Green genes (v13_5) as references for yeast and prokaryotes, respectively. The microbial diversity was calculated and reported as Alpha and Beta analyses (Supplementary Figure 1S). Taxonomy assignments of OTU sequences were verified using BLAST (16S ribosomal RNA and nr databases). Microbial relative abundances in different samples are graphically represented as heat maps using the Multi Experiment Viewer software (MeV 4.9.0) (18). This study focused on the highly abundant OTUs (i.e. relative abundances higher than $1 \%$ and $0.5 \%$ with respect to the total number of sequences for bacteria and yeast, respectively) and bacteria and yeast are discussed separately in this paper. Statistical evaluations were computed with the Excel Data Analysis tool.

This article is protected by copyright. All rights reserved. 


\section{Analytical methods}

The biomass was harvested by centrifugation at $1585 \times \mathrm{g}$ for $15 \mathrm{~min}$ and dried at $60^{\circ} \mathrm{C}$ to constant weight. The specific growth rate was determined by calculating the difference in log of the biomass over time corresponding to the exponential growth phase. A straight line was obtained with a slope equal to the specific growth rate and the intercepts equal to the lag phase time. To extract the lipids, a mixture of chloroform and methanol $(2: 1, v / v)$ as solvents were added into the dried biomass and sonicated for $1 \mathrm{~h}$. The solvents were evaporated and the lipids extracted were weighed. Then, the lipid production, lipid content and lipid yield were calculated. The extracted lipids were transesterified into fatty acid methyl ester (FAME) and analyzed for their fatty acid compositions using a gas chromatograph equipped with a capillary column (Hewlett Packard Plus 6850 series, Agilent, USA) and a flame ionization detector. The detector temperature was $300^{\circ} \mathrm{C}$. The column temperature was set at $210^{\circ} \mathrm{C}$ and held for $12 \mathrm{~min}$ before being increased to $250^{\circ} \mathrm{C}$ at a rate of 20 ${ }^{\circ} \mathrm{C} / \mathrm{min}$, and then held for $8 \mathrm{~min}$.

The cell-bound lipase activity was determined based on hydrolytic activity. The wet cells were added with $0.2 \mathrm{~mL}$ of phosphate buffer $(\mathrm{pH} 7.0,50 \mathrm{mM})$ and $0.5 \mathrm{~mL}$ of substrate (the mixture of $10 \% \mathrm{w} / \mathrm{v}$ palm oil in iso-octane). Then the reaction was performed by mixing the mixture on a high speed vortex at $1,000 \mathrm{rpm}$ and room temperature $\left(30 \pm 2^{\circ} \mathrm{C}\right)$ for $30 \mathrm{~min}$. Afterwards, $0.2 \mathrm{~mL}$ of 6 $\mathrm{M} \mathrm{HCl}$ was added and the upper phase was immediately taken and measured by spectrophotometer at $715 \mathrm{~nm}$. The absorbance values were calculated amount of occurring free fatty acids using standard curve of palmitic acid. One unit of enzyme is defined as the amount of enzyme that hydrolyzes palm oil and releases free fatty acids in form of palmitic acid $1.0 \mu$ mole per min at the specified condition.

This article is protected by copyright. All rights reserved. 
Flocculation efficiency was determined according to the modified procedure of Mandik et al. (19). The culture broth was vortexed and settle for $60 \mathrm{~min}$. The supernatant from half of the height of the culture broth in tube $(16 \times 150 \mathrm{~mm}$, Pyrex, USA) was taken and measured for OD at $660 \mathrm{~nm}$ and then the flocculation efficiency was calculated based on the decrease of the OD.

All experiments were performed at least in triplicates. The significance of the experimental results was evaluated by one-way analysis of variance (ANOVA) and Duncan's multiple range tests ( $P$ $<0.05)$.

\section{Results and Discussion}

\section{Successive-batch fermentation of sterile wastes with different levels of medium replacement}

\section{Y. lipolytica TISTR 5151 was used in successive-batch fermentation of sterile industrial}

wastes. The batch fermentation was repeated by replacing culture broth with fresh medium every $72 \mathrm{~h}$. Three fractions of medium replacement were applied, namely $50 \%, 70 \%$ and $90 \%$ volume substitution of the total volume. The profiles of the biomass, production of lipids and cell-bound lipase are shown in Figure 1. The yeast grew continuously and produced lipids and cell-bound lipase during all 5 cycles of successive-batch fermentation. With the $50 \%$ medium replacement, the initial and final biomass in each cycle were higher than those with $70 \%$ and $90 \%$ medium replacement. The lipid content of the biomass tended to decrease with the number of cultivation repetitions. The cell-bound lipase was highest in the first batch and decreased to be in a range of $250-300 \mathrm{U} / \mathrm{L}$ during the $2^{\text {nd }}-5^{\text {th }}$ cycles of cultivation (Figure 1a). With $70 \%$ medium replacement, the initial and final biomasses in each cycle were slightly lower than those with $50 \%$ medium replacement but the lipid content continuously increased with the number of cultivation repetitions (Figure 1b).

This article is protected by copyright. All rights reserved. 
Increasing the medium replacement to $90 \%$ produced final biomass and lipids lower than those at $50 \%$ and $70 \%$, due to the lower initial yeast cell concentration in each cycle (Figure 1c).

Table 1 summarizes the performance of the successive-batch fermentation with different levels of medium replacement. The total recovery of biomass and lipids depended on their concentration and recovered volume. Although medium replacement at $50 \%$ achieved higher final biomass and lipid production (Figure 1), as the percent recovered volume was only $50 \%$ of the total volume the biomass and lipids recovered were then lower than those at $70 \%$ medium replacement. The five cycles of successive-batch fermentation with $70 \%$ medium replacement were found to produce the best performance demonstrating the highest level of total recovered biomass $(18.6 \pm 0.01 \mathrm{~g})$ and lipids $(10.54 \pm 0.53 \mathrm{~g})$. Due to the higher volume of medium recovery, the yeast grew faster with a higher specific growth rate of $0.46-0.57 d^{-1}$. The biomass and lipid yields based on the COD consumed were also highest at $0.203 \pm 0.001 \mathrm{~g} / \mathrm{g}-\mathrm{COD}$ and $88.96 \pm 5.76 \mathrm{mg} / \mathrm{g}-\mathrm{COD}$, respectively. The glycerol consumption was in the range of 83-90\%. The cell-bound lipase activity was increased by increasing the percentage medium replacement from $50 \%$ to $70 \%$. This might be related to the increased oil supplementation at higher levels of medium replacement. More than 92 $\%$ of the yeast cells were flocculated after gravity settling for $60 \mathrm{~min}$. This property would thus reduce the cost of cell recovery (20). The result indicates that $Y$. lipolytica could be used in successive-batch fermentation for the effective biovalorization of industrial wastes into lipids and lipase.

This article is protected by copyright. All rights reserved. 


\section{Successive-batch fermentation under non-sterile condition}

The ability to outcompete microbial contaminants and to be the dominant microorganism under non-sterile conditions would strongly affect the performance of $Y$. lipolytica. In this study, to assess that ability the successive-batch fermentation with $70 \%$ medium replacement was performed using non-sterile wastes (Figure 2a). The successive-batch fermentation without $Y$. lipolytica inoculation was also performed (Figure 2b). Without $Y$. lipolytica inoculation, the biomass concentrations were lower and there was no lipase activity detected. Although lipid productions were detected, their levels were much lower than those with $Y$. lipolytica inoculation. These results indicate the effective lipid and lipase production by Y. lipolytica.

Table 1 compares the performance of the processes under sterile and non-sterile conditions at $70 \%$ medium replacement. The non-sterile effluent led to a higher total recovery of biomass $(28.1 \pm 0.06 \mathrm{~g})$ and lipids $(18.4 \pm 1.12 \mathrm{~g})$ than the sterile effluent. The biomass increased faster with the highest specific growth rate of $0.64 \pm 0.33 \mathrm{~d}^{-1}$. The maximum biomass yield was $0.213 \pm 0.07 \mathrm{~g}$ per gCOD with the maximum lipid yield being $146.2 \pm 46.5 \mathrm{mg}$ per g-COD. However, the cell-bound lipase activity using non-sterile effluent decreased to $170.74 \pm 32 \mathrm{U} / \mathrm{L}$. Interestingly, the COD removal and oil removal in the non-sterile system (at the same $70 \%$ medium replacement) were higher than those in the sterile system. These results indicate the effective bioaugmentation of oily industrial wastes by Y. lipolytica and indigenous strains. The lower glycerol consumption was possibly due to microbial community changes in the non-sterile system.

A total plate count for bacteria and yeasts was performed to evaluate their changes during the five cycles (Figure 3). Although the inoculated yeast cells were found in higher numbers compared to the bacteria detected during the $1^{\text {st }}$ and $2^{\text {nd }}$ cycles, the number of bacterial cells became dominant in later cycles. This could have been due to the fact that the cell division of This article is protected by copyright. All rights reserved. 
bacteria was faster than that of the yeast. Interestingly, lipids were continuously produced along with increased biomass while the lipase production decreased significantly in the $3^{\text {rd }}$ cycle. Table 2 shows the fatty acid composition of the lipids from both cultivations. The extracted lipids consisted of two main fatty acids, oleic acid (C18:1) and palmitic acid (C16:0). The similarity of the fatty acid compositions of lipids produced by yeast to those of palm oil might be due to the ex novo synthesis pathway in which the yeast assimilates fatty acids in palm oil industrial wastes and directly accumulates them as cellular lipids. There was no significant difference between the composition of fatty acids in each repeated-batch but when using non-sterile effluent, the concentration of palmitic acid decreased while that of oleic acid increased, especially in the $3^{\text {rd }}, 4^{\text {th }}$ and $5^{\text {th }}$ cycles. The lipids with a high content of unsaturated fatty acids (oleic acid) are associated with better cold-flow properties. These results indicate the potential for the use of lipids extracted as biodiesel feedstocks.

Table 3 summarizes the previous reports of yeast cultivations under non-sterile conditions. Chi et al. (21) reported the cultivation of three different yeasts, Candida curvatus ATCC 20509, Rhodotorula glutinis ATCC 204091 and Yarrowia lipolytica ATCC 20460 in sterile and non-sterile municipal wastewater. They found that the biomass and lipids in both conditions were not significantly different. In the study of Santamauro et al. (3), the use of a non-sterile medium produced a lower biomass and lipid accumulation possibly due to substrate competition with indigenous microorganisms. The present study has shown the potential use of $Y$. lipolytica TISTR 5151 in the successive-batch fermentation of non-sterile effluent for lipid and lipase production. However, the increase in biomass and lipid production of this bioconversion under non-sterile condition should be clarified for the further development of the process to an industrial scale. 


\section{Microbial community changes}

Contamination with indigenous microorganisms is unavoidable when using non-sterile wastes. In this study, it was obvious that the plate-counting method could not be used for meticulous microbial identification. Therefore, to overcome the cultivation challenges, $Y$. lipolytica TISTR 5151 and the indigenous microbes in the industrial wastes were monitored by a deep amplicon sequencing of the ITS region and 16S rRNA gene. Figure 4 shows the abundance of yeast strains identified in each cycle and the changes in their relative abundance during successive-batch fermentation. The community was composed of 65 yeast strains. Considering a threshold of $0.5 \%$ of relative abundance, only 9 yeast strains were considered as dominant (Figure 4). The OTU assigned to the genus Yarrowia, present in all the repeated-cycles, was verified using the NCBI database and identified as $100 \%$ similar to Yarrowia lipolytica. Therefore, the decrease in lipase activity during the $4^{\text {th }}$ and $5^{\text {th }}$ cycles might be due to the decrease of this particular yeast species.

Among the indigenous yeasts identified there were number of oleaginous species that have been previously reported by other researchers (22-24). It is possible that the presence of these indigenous oleaginous species might have contributed to the increased lipid production during successive-batch fermentation. It should be noted that the palm oil industrial wastes used in this study have previously been reported as representing a suitable medium for lipid accumulation by yeasts (17). Figure 4 indicates the detection of Saccharomycetales sp. 13. This order was identified as being $100 \%$ similar to two different species, Kodamaea ohmeri and Pichia guilliermondii. High relative abundance of $89.85 \pm 0.04 \%, 92.46 \pm 0.04 \%$ and $89.67 \pm 0.01 \%$ were obtained in the $1^{\text {st }}$ batch (B1), $2^{\text {nd }}$ batch (B2) and $3^{\text {rd }}$ batch (B3), respectively. Saccharomycetales $s p .30$, which was identified as $100 \%$ similar to the genera Metschnikowia and Candida, was also found in high abundance.

During the first 3 cycles of the successive-batch fermentation, the abundance did not significantly 
change, but in the $5^{\text {th }}$ cycle this order significantly increased by 3.6 times $(p<0.01)$ and reached a relative abundance of $25.04 \pm 0.02 \%$.

Figure 5 shows the abundance of bacteria identified in each cycle and the changes in their relative abundance during successive-batch fermentation. It was found that 638 bacterial OTUs were present in the five cycles. Based on a $1 \%$ threshold of relative abundance, 35 microbes were considered as dominant. The indigenous bacterial community could be clearly divided into 3 groups; stable, favored and inhibited. Half of the indigenous bacteria belonged to the stable and inhibited groups (i.e. Xanthobacteraceae sp., Rhizobiaceae sp.). The members of these groups are considered as nitrogen-fixing bacteria, which establish symbiotic associations with plants $(25,26)$. Nevertheless, during the first 3 cycles of repeated-batch, the favored species such as Rummeliibacillus suwonensis 370 were found with high relative abundance of $45.89 \pm 0.02 \%, 56.39 \pm 0.01 \%$ and $47.13 \pm 0.01 \%$ in the $1^{\text {st }}$ batch (B1), $2^{\text {nd }}$ batch (B2) and $3^{\text {rd }}$ batch (B3), respectively. This species belongs to the family Bacillaceae and was most closely affiliated with Rummeliibacillus pynus (97.4 \%) (27). R. pynus has previously been isolated from palm oil mill wastes and has been reported to be able to produce polymer polyhydroxyalkanoate, which also has potential to be used as a feedstock for biodiesel production (28). However, as the bacterial cells are very small and have a low cell weight, $R$. suwonensis may make only a minor to lipid production. In the $5^{\text {th }}$ cycle (C5), R. suwonensis 370 significantly decreased with a concomitant increase in the favored species, Serratia sp. 376, which was identified as $100 \%$ similar to the species, Serratia marcescen and Serratia nematodiphila. More specifically, Serratia sp. 376 was the most dominant species of the community having a relative abundance equal to $64.22 \pm 0.01 \%$.

In addition, members of the order Clostridiales and Bacillales, such as Clostridium populeti 109, Clostridium sp. 433, and Bacillus sp. 297, all of which belonged to the favored and stable 
groups, were detected in almost all the cycles. In fact, the members of these orders are obligate and facultative anaerobes. However, they possibly grew and increased in number due to the decrease in dissolved oxygen during yeast growth and effluent replacement. The species Clostridium sp. 433, which was identified as $100 \%$ similar to Clostridium puniceum has been reported to be a cellulolytic/pectinolytic producers, with the ability to generate sugar from lignocellulosic biomass as well as the species Clostridium populeti (29). Bacillus sp. 297 was identified as $100 \%$ similar to Bacillus coagulans and Bacillus badius which have been reported as lipase and protease producer, having the ability to convert oil and protein into fatty acids and amino acids $(30,31)$. These enzymes favor the substrate assimilation by other microorganisms. Some species of Serratia and Bacillus have been reported as producers of several types of biosurfactants such as prodigiosin and serrawettin $(32,33)$. Generally, surfactants are applied in oil degradation through emulsification mechanism $(34,35)$ and also as carbon source $(36)$. When oil is covered by surfactant to form an emulsion $(34)$, when the emulsion is assimilated by an oleaginous species, both molecules are used as carbon sources.

\section{Conclusions}

This study has shown the potential use of oleaginous yeast $Y$. lipolytica for the bioaugmentation and biovalorization of non-sterile industrial wastes into lipids and lipase. Five cycles of non-sterile successive-batch fermentation with $70 \%$ medium replacement was found to be the most effective system for the removal of COD and oil as well as for forming valuable products. Changes in the microbial community provided new insights into the dynamics of target strains and their interaction with indigenous strains in the non-sterile system. Y. lipolytica was able to be 
retained in the system until the fifth cycle of successive-batch fermentation. Moreover, other minor oleaginous microbes were also detected and might also contribute to lipid production.

\section{Conflicts of interest}

The authors have no conflicts of interest to declare regarding this manuscript.

\section{Acknowledgements}

This research was financially supported by the Graduate School of Prince of Songkla University and the Thai government under Grant No. AGR600494S. The first author was supported by the Strategic Scholarships for Frontier Research Network for the Ph.D. Program Thai Doctoral degree from the Office of the Higher Education Commission and the Energy Conservation Promotion Fund. The second author was supported by the Thai Research Fund under Grant No. RTA6280014.

This article is protected by copyright. All rights reserved. 


\section{References}

(1) Z. Cheng, X.M. Liqun, X. Hongqing, X. M. Li. Nutrition effects on the biofilm immobilization and 3,5DNBA degradation of Comamonas testosteroni A3 during bioaugmentation treatment, Biotechnol. Appl. Biochem.62 (2014)

(2) Y. Louhasakul, B. Cheirsilp, P. Prasertsan, P. Valorization of palm oil mill effluent into lipid and cell-bound lipase by marine yeast Yarrowia lipolytica and their application in biodiesel production, Waste Biomass Valor. 7 (2016) 417-426.

(3) F. Santamauro, F. M. Whiffin, R. J. Scott, C. J. Chuck, Low-cost lipid production by an oleaginous yeast cultured in non-sterile conditions using model waste resources, Biotechnol. Biofuels 7 (2014) $34-43$.

(4) H. W. Yen, Y. T. Liao, Y. X. Liu, The growth of oleaginous Rhodotorula glutinis in an airlift bioreactor on crude glycerol through a non-sterile fermentation process, Bioprocess Biosyst. Eng. 38 (2015) 1541 - 1546.

(5) J. M. Ageitos, J. A. Vallejo, P. Veiga-Crespo, T. G. Villa, Oily yeasts as oleaginous cell factories, Appl. Microbiol. Biotechnol. 90 (2011) 1219 - 1227.

(6) A. F. Aravantinou, I. D. Manariotis, Effect of operating conditions on Chlorococcum sp. growth and lipid production, J. Environ. Chem. Eng. 4(1) (2016) 1217-1223.

(7) S. Kumar, N. Gupta, K. Pakshirajan, Simultaneous lipid production and dairy wastewater treatment using Rhodococcus opacus in a batch bioreactor for potential biodiesel application, J. Environ. Chem. Eng. 3(3) (2015) 1630-1636.

This article is protected by copyright. All rights reserved. 
(8) L. Xiong, C. Huang, X. F. Chen, W. X. Hu, X. D. Chen, Comparison of fermentation by mono-culture and co-culture of oleaginous yeasts for ABE (acetone- butanol- ethanol) fermentation wastewater treatment, J. Environ. Chem. Eng. 4(4) (2016) 3803-3809.

(9) R. Bussamara, M. A. Fuentefria, E. S. deOliveira, L. Broetto, M. Simcikova, P. Valente, A. Schrank, M. H. Vainstein, Isolation of a lipase-secreting yeast for enzyme production in a pilot-plant scale batch fermentation, Bioresour. Technol. 101(1) (2010) 268 - 275.

(10) P. Hugenholtz, Exploring prokaryotic diversity in the genomic era, Genome Biol. 3(2) (2002) 1 -

8.

(11) A. Moura, M. Tacao, I. Henriques, J. Dias, P. Ferreira, A. Correia, Characterization of bacterial diversity in two aerated lagoons of a wastewater treatment plant using PCR-DGGE analysis, Microbiol. Res. 164 (2007) 560 - 569.

(12) J. Barriuso, J. R. Valverde, P. R. Mellado, Estimation of bacterial diversity using next generation sequencing of 16S rDNA: a comparison of different workflows, Bioinformatics. 12 (2014) 478.

(13) G. Luo, D. De Francisci, P. G. Kougias, T. Laura, X. Zhu, I. Angelidaki, New steady-state microbial community compositions and process performances in biogas reactors induced by temperature disturbances, Biotechol. Biofuel. 8(1) (2015) 3.

(14) N. J. Loman, R. V. Misra, T. J. Dallman, C. Constantinidou, S. E. Gharbia, J. Wain, M. J. Pallen, Performance comparison of benchtop high-throughput sequencing platforms, Nat. Biotechnol. 30(5) (2012) $434-439$.

This article is protected by copyright. All rights reserved. 
(15) A. Schöler, S. Jacquiod, G. Vestergaard, S. Schulz, M. Schloter, Analysis of soil microbial communities based on amplicon sequencing of marker genes, Biol. Fert. Soils. 53(5) (2017) 485489.

(16) X. Zhao, C. M. Hu, S. G. Wu, H. W. Shen, Z. B. Zhao, Lipid production by Rhodosporidium toruloides Y4 using different substrate feeding strategies, J. Ind. Microbiol. Biotechnol. 38 (2011) $627-632$.

(17) Y. Louhasakul, B. Cheirsilp, Industrial wastes as a promising renewable source for production of microbial lipid and direct transesterification of the lipid into biodiesel, Bioresour. Technol. 142(2013) 329-337.

(18) A. I. Saeed, N. K. Bhagabati, J. C. Braisted, W. Liang, V. Sharov, E. A. Howe, J. Li, M. Thiagarajan, J. A. White, J. Quackenbush, TM4 microarray software suite, Methods Enzymol. 411 (2006) 134193.

(19) Y. I. Mandik, B. Cheirsilp, P. Boonsawang, P. Prasertsan, Optimization of flocculation efficiency of lipid-rich marine Chlorella sp. biomass and evaluation of its composition in different cultivation modes, Bioresour. Technol. 182 (2015) 89-97.

(20) Y. Louhasakul, B. Cheirsilp, S. Maneerat, P. Prasertsan, Potential use of flocculating oleaginous yeasts for bioconversion of industrial wastes into biodiesel feedstocks, Renew. Energy. 136 (2019) 1311-1319.

(21) Z. Chi, Y. Zheng, A. Jiang, S. Chen, Lipid production by culturing oleaginous yeast and algae with food waste and municipal wastewater in an integrated process, Appl. Biochem. Biotechnol. 165(2) (2011) 442-453.

This article is protected by copyright. All rights reserved. 
(22) S. Kitcha, B. Cheirsilp, Screening of oleaginous yeasts and optimization for lipid production using crude glycerol as a carbon source, Energy Procedia. 9 (2011) 274 - 282.

(23) M. Taccari, L. Canonico, F. Comitini, I. Mannazzu, M. Ciani, Screening of yeasts for growth on crude glycerol and optimization of biomass production, Bioresour. Technol. 110 (2012) 488 - 495.

(24) S. Tampitak, Y. Louhasakul, B. Cheirsilp, P. Prasertsan, Lipid production from hemicellulose and holocellulose hydrolysate of palm empty fruit bunches by newly isolated oleaginous yeasts, Appl. Biochem. Biotechnol. 176 (2015) 1801 - 1814.

(25) A. Oren, The Family Xanthobacteraceae. In The Prokaryotes Alphaproteobacteria and Betaproteobacteria, The $4^{\text {th }}$ edition. p. (2014) 709-726. Springer. Berlin. Heidelberg.

(26) L. M. C. Alves, J. A. M. de Souza, A. de Mello Varani, E. G. de Macedo Lemos, The Family Rhizobiaceae. In The Prokaryotes Alphaproteobacteria and Betaproteobacteria, The $4^{\text {th }}$ edition (2014) 419-437. Springer Berlin Heidelberg.

(27) J. Her, J. Kim, Rummeliibacillus suwonensis sp. nov., Isolated from soil collected in a mountain area of South Korea, J. Microbiol. 51(2) (2013) 268 - 272.

(28) P. Junpadit, T. T. Suksaroj, P. Boonsawang, Transformation of palm oil mill effluent to terpolymer polyhydroxyalkanoate and biodiesel using Rummeliibacillus pycnus strain $\mathrm{TS}_{8}$, Waste Biomass Valor. 8(4) (2017) 1247-1256.

(29) R. A. Holt, A. J. Cairns, J. G. Morris J. G. Production of butanol by Clostridium puniceum in batch and continuous culture, Appl. Microbiol. Biotechnol. 27(4) (1988) 319-324.

This article is protected by copyright. All rights reserved. 
(30) S. Kumar, K. Kikon, A. Upadhyay, S. S. Kanwar, R. Gupta, Production, purification, and characterization of lipase from thermophilic and alkaliphilic Bacillus coagulans BTS-3, Protein. Expr. Purif. 41 (2015) 38-44.

(31) K. Rao, Y. P. Devi, M. L. Narasu, A new acidic protease from Bacillus badius, J. Aqua. Biol. 22(1) (2007) 1-6.

(32) M. Ines, G. Dhouha, Lipopeptides biosurfactants: mean classes and new insights for industrial, biomedical, and enviromental applications, Biopolymers. 104(3) (2015) 129 - 147.

(33) C. Su, Z. Xiang, Y. Liu, X. Zhao, Y. Sun, Z. Li, L. Li, F. Chang, T. Chen, X. Wen, Y. Zhou, F. Zhao, Analysis of the genomic sequences and metabolites of Serratia surfactantfaciens sp. nov. YD25 $5^{\top}$ that simultaneously produces prodigiosin and serrawettin W2, BMC Genomics. 17 (2016) 865.

(34) M. Mishra, P. Muthuprasanna, K. S. Prabha, P. S. Rani, I. A. Satish babu, Ch. I. S. Chandiran, G. Arunachalam, S. Shalini, Basics and potential applications of surfactants - a review, Int. J. Pharm. Tech. Res. 1(4) (2009) 1354 - 1365.

(35) I. E. Affandi, N. H. Suratman, S. Abdullah, W. A. Ahmad, Z. A. Zakaria, Degradation of oil and grease from high-strength industrial effluents using locally isolated aerobic biosurfactantproducing bacteria, Int. Biodeterior. Biodegradation 95 (2014) 33 - 40.

(36) Y. Taoka, N. Nagano, Y. Okita, H. Izumida, S. Sugimoto, M. Hayashi, Effect of Tween 80 on the growth, lipid accumulation and fatty acid composition of Thraustochytrium aureum ATCC 34304 , J. Biosci. Bioeng. 111(4) (2011) 420 - 424.

This article is protected by copyright. All rights reserved. 


\section{Figure legends}

Figure 1 Effect of different medium replacements on biomass (bar) and production of lipids (open circle) and cell-bound lipase (closed circle) by Y. lipolytica TISTR 5151 during ssuccessivebatch fermentation of sterile wastes. Data are expressed as means of triplicate experiments and their standard deviations.

(a) $50 \%$ medium replacement

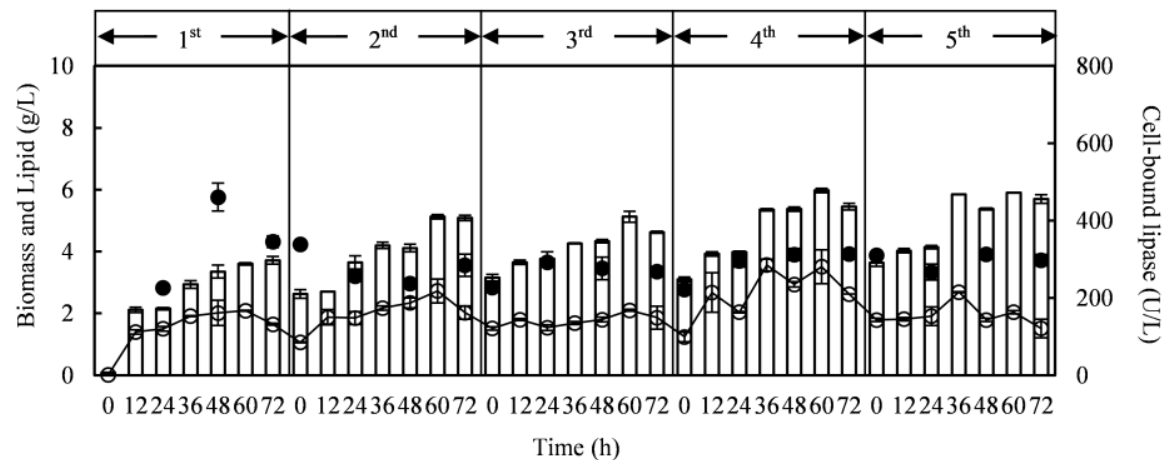

(b) $70 \%$ medium replacement

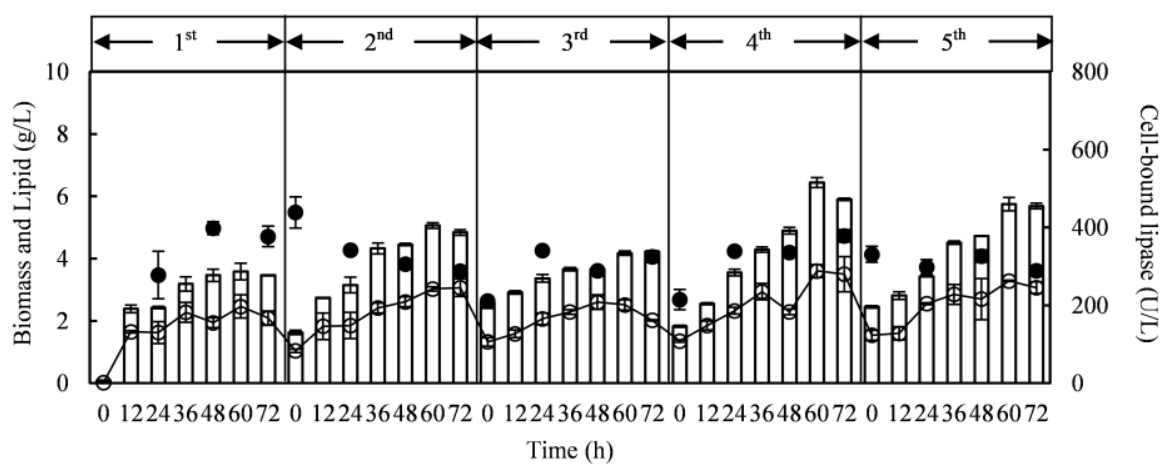

(c) $90 \%$ medium replacement

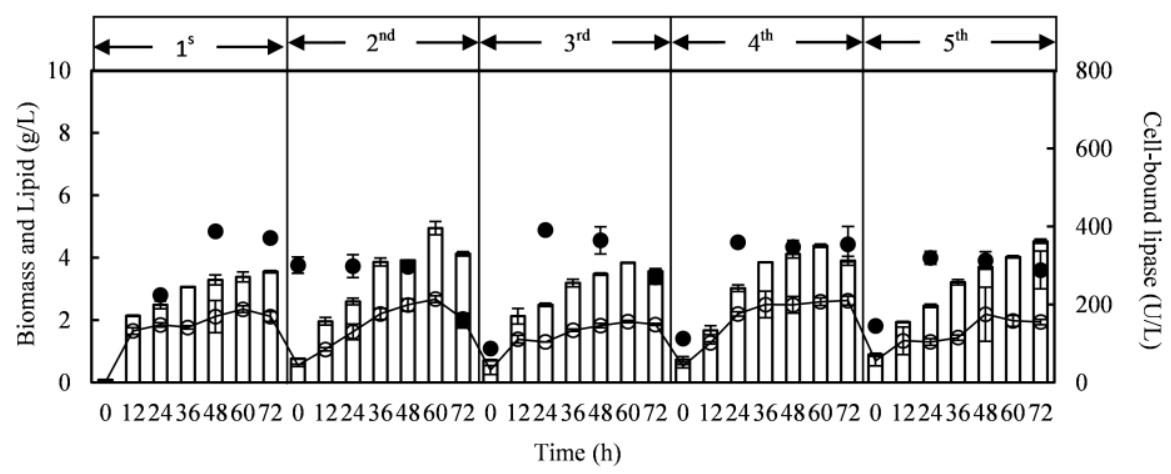

This article is protected by copyright. All rights reserved. 
Figure 2 Non-sterile successive-batch fermentation with yeast inoculation (a) and without yeast inoculation (b). Biomass (bar) and production of lipids (open circle) and cell-bound lipase (closed circle). The medium replacement was 70\%. Data are expressed as means of triplicate experiments and their standard deviations.

(a) With yeast inoculation

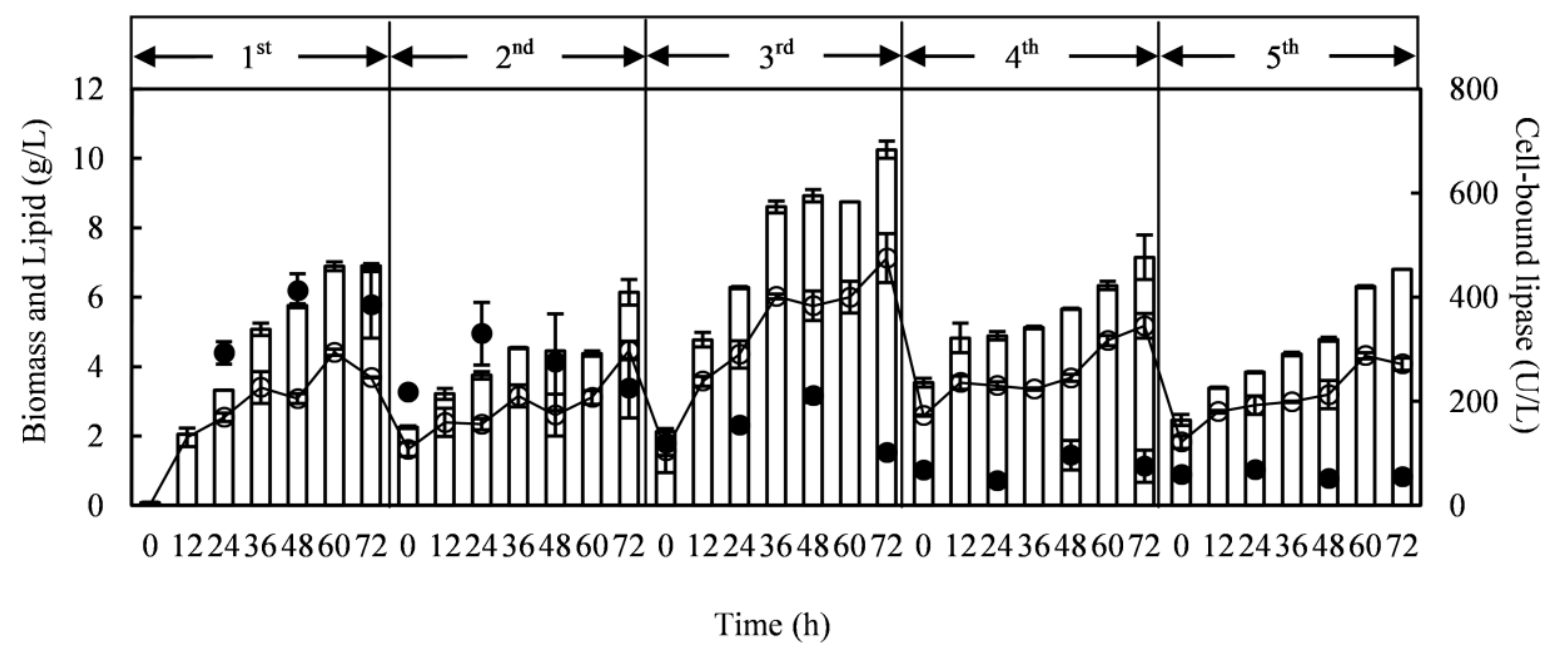

(b) Without yeast inoculation

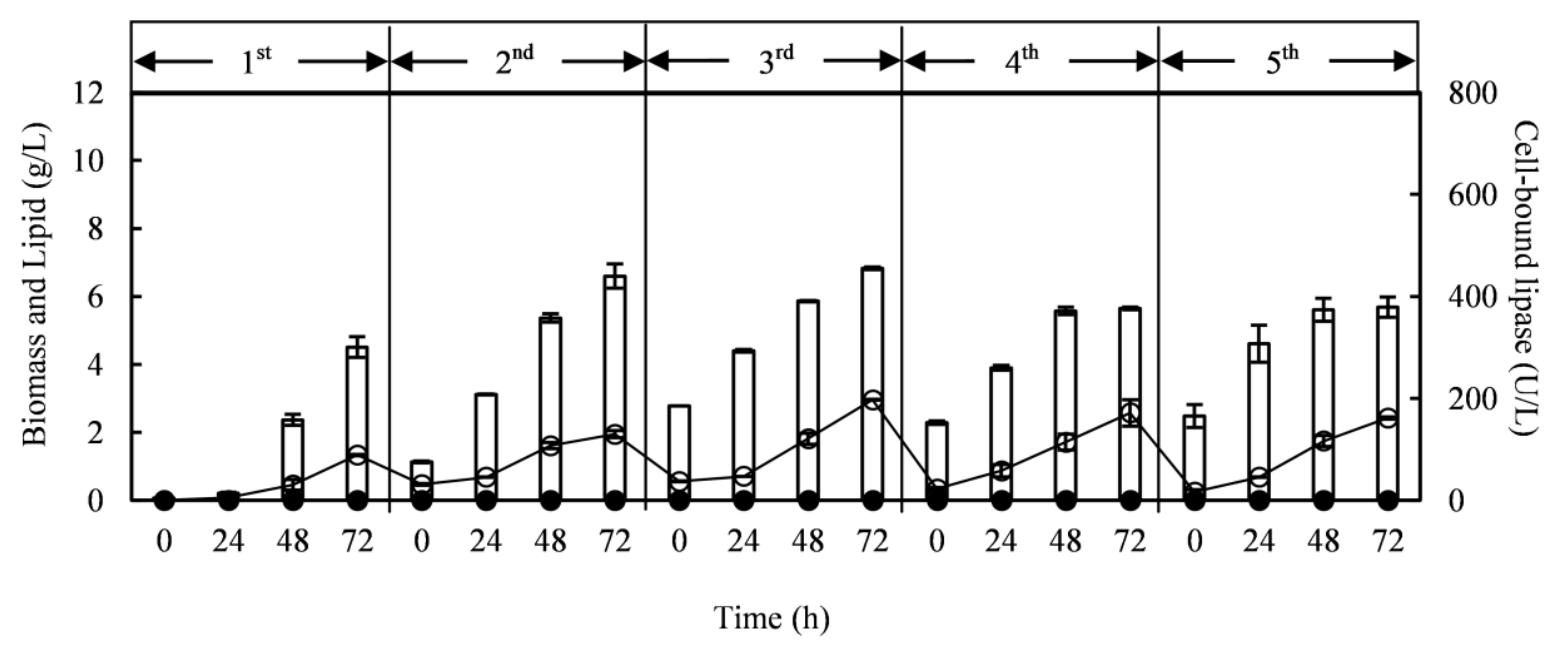

This article is protected by copyright. All rights reserved. 
Figure 3 Number of yeast and bacteria during non-sterile successive-batch fermentation. Data are expressed as means of triplicate experiments and their standard deviations.

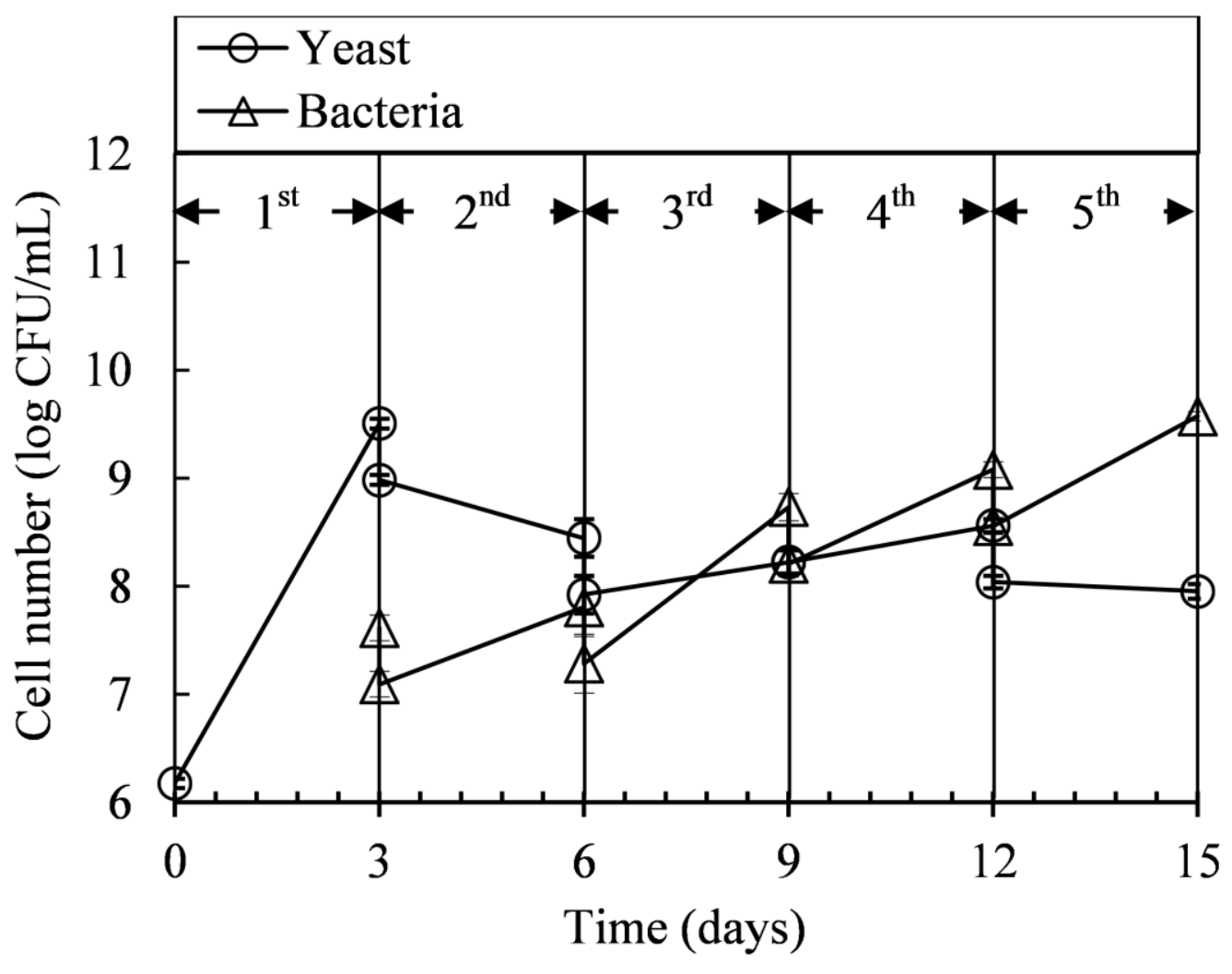

This article is protected by copyright. All rights reserved. 
Figure 4 Frequency of yeasts identified in different batches during successive-batch fermentation (on the left panel starts from the $1^{\text {st }}$ batch (B1), $2^{\text {nd }}$ batch (B2), $3^{\text {rd }}$ batch (B3) and $5^{\text {th }}$ batch (B5) compared to pure culture of $Y$. lipolytica TISTR 5151, control), and fold changes of number of sequences compared with the $1^{\text {st }}$ batch (on the right panel). Data are expressed as means of triplicate experiments and their standard deviations. Color scales are shown on top of each panel. On the left panel, red color indicates the high relative abundance and blue and black color indicate the low relative abundance. On the right panel, red, green and black color indicate high change or increase in fold change, low change or decrease in fold change and no change, respectively. The asterisks close to the fold change panel indicate the significance of the batch effects, $\left(* p<0.05 ;{ }^{* *} p<0.01 ; * * * p<0.001\right)$, on the variation in average yeast abundance.

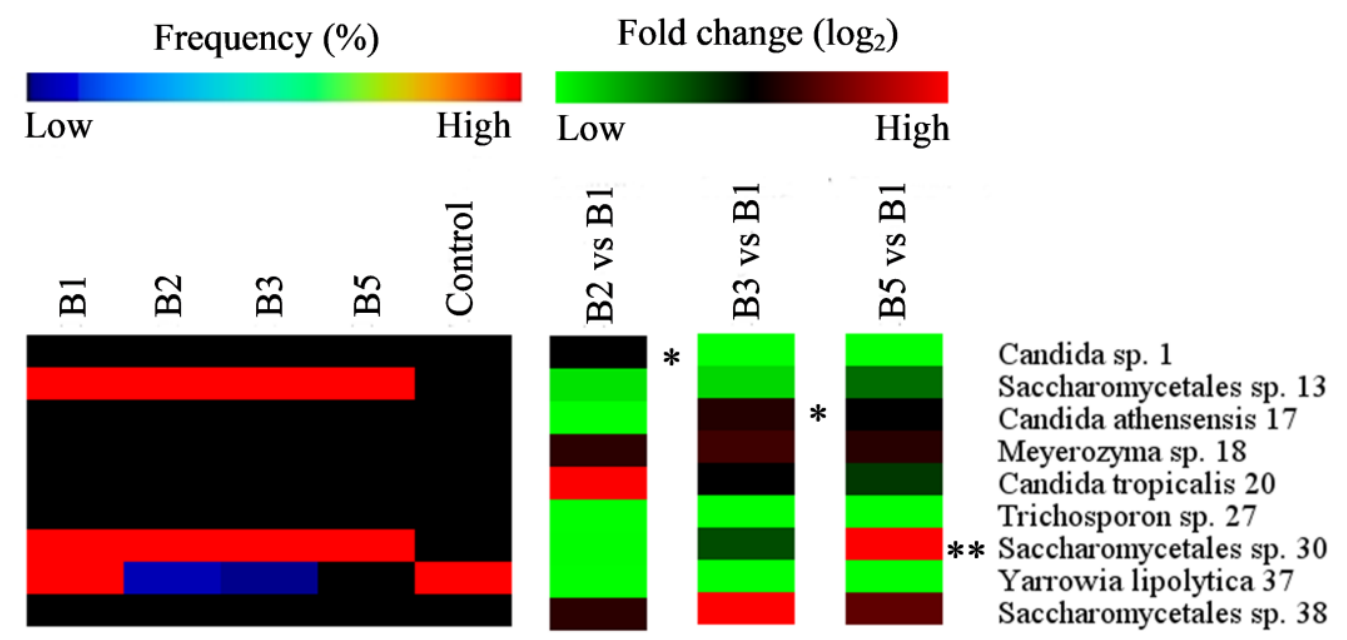

This article is protected by copyright. All rights reserved. 
Figure 5 Frequency of bacteria identified in different batches during successive-batch fermentation (on the left panel starts from the $1^{\text {st }}$ batch $(B 1), 2^{\text {nd }}$ batch $(B 2), 3^{\text {rd }}$ batch (B3) and $5^{\text {th }}$ batch (B5), and fold changes of number of sequences compared with the $1^{\text {st }}$ batch (on the right panel). Data are expressed as means of triplicate experiments and their standard deviations. Color scales are shown on top of each panel. On the left panel, red color indicates the high relative abundance and blue and black color indicate the low relative abundance. On the right panel, red, green and black color indicate high change or increase in fold change, low change or decrease in fold change and no change, respectively. The asterisks close to the fold change panel indicate the significance of the batch effects, ( $^{*}$ $\left.p<0.05 ;{ }^{* *} p<0.01 ;{ }^{* *} p<0.001\right)$, on the variation in average bacteria abundance.

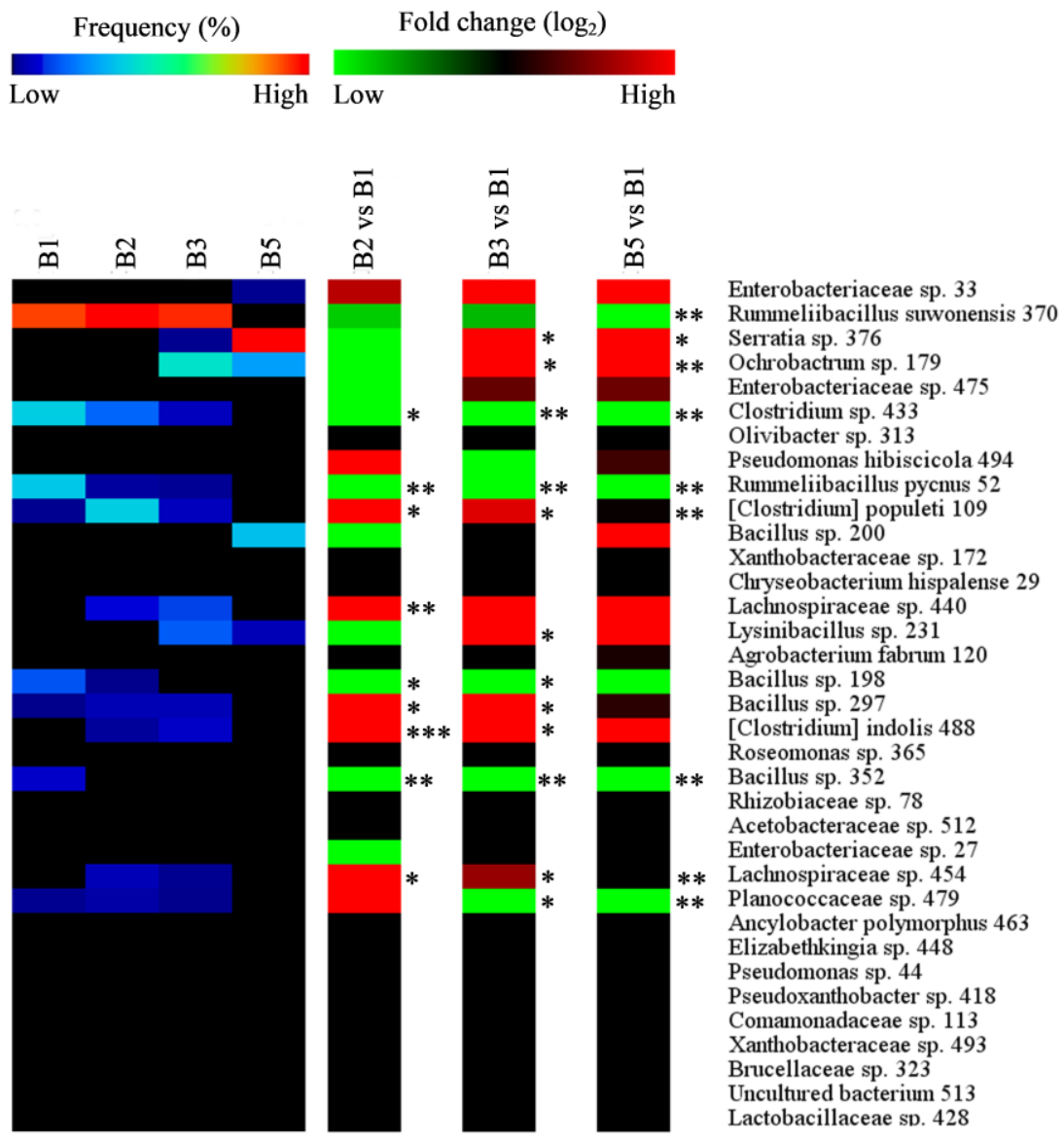

This article is protected by copyright. All rights reserved. 
Yarrowia lipolytica Non-sterile successive batch fermentation

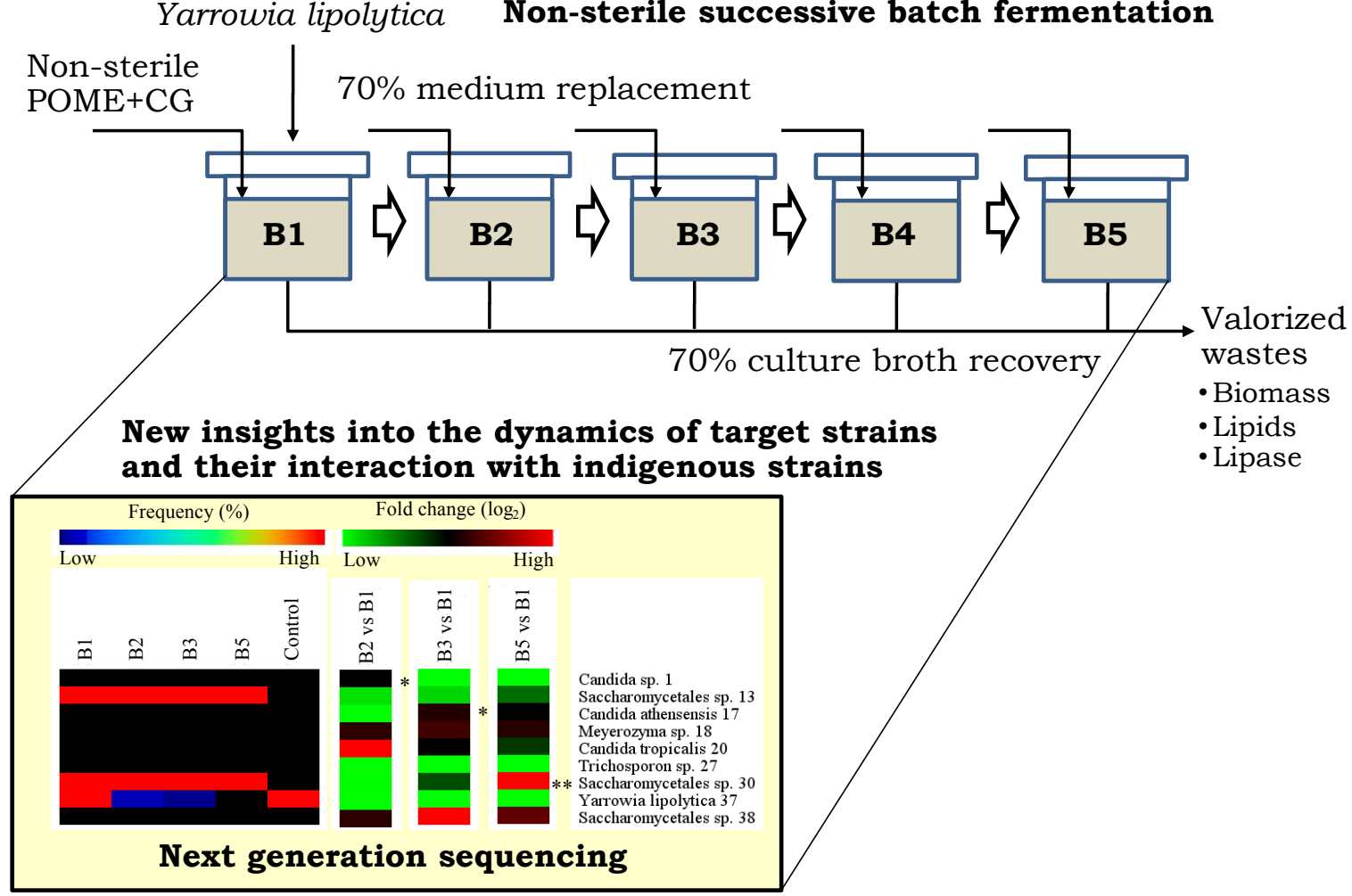

Highlights

- Lipolytic oleaginous yeast Yarrowia lipolytica is promising for bioaugmentation

- Successive-batch fermentation with optimal medium replacement was proposed

- Metagenomic sequencing provided new insights into the dynamics of target strain

- Y. lipolytica is robust and effective in non-sterile successive-batch fermentation

This article is protected by copyright. All rights reserved. 
Table 1 Performance of the successive-batch fermentations by Y. lipolytica TISTR 5151 with different medium replacements

\begin{tabular}{lcccc}
\hline Parameters & \multicolumn{3}{c}{ Sterile } & Non-sterile \\
\cline { 2 - 5 } & $50 \%$ medium & $70 \%$ medium & $90 \%$ medium & $70 \%$ medium \\
& replacement & replacement & replacement & replacement \\
\hline Total recovered biomass (g) & $15.1 \pm 0.21^{\mathrm{c}}$ & $18.6 \pm 0.01^{\mathrm{b}}$ & $18.2 \pm 0.15^{\mathrm{b}}$ & $28.1 \pm 0.06^{\mathrm{a}}$ \\
Total recovered lipid (g) & $5.71 \pm 0.44^{\mathrm{c}}$ & $10.5 \pm 0.53^{\mathrm{b}}$ & $9.71 \pm 0.15^{\mathrm{b}}$ & $18.4 \pm 1.12^{\mathrm{a}}$ \\
Specific growth rate (d $\left.{ }^{-1}\right)$ & $0.32 \pm 0.10^{\mathrm{b}}$ & $0.46 \pm 0.12^{\mathrm{a}}$ & $0.57 \pm 0.18^{\mathrm{a}}$ & $0.64 \pm 0.33^{\mathrm{a}}$ \\
Biomass yield (g/g-COD) & $0.164 \pm 0.002^{\mathrm{b}}$ & $0.203 \pm 0.001^{\mathrm{a}}$ & $0.168 \pm 0.001^{\mathrm{b}}$ & $0.213 \pm 0.07^{\mathrm{a}}$ \\
Lipid yield (mg/g-COD) & $72.1 \pm 10.2^{\mathrm{c}}$ & $88.9 \pm 5.76^{\mathrm{b}}$ & $39.5 \pm 1.63^{\mathrm{d}}$ & $146.2 \pm 46.5^{\mathrm{a}}$ \\
Cell-bound lipase (U/L) & $296.3 \pm 55.2^{\mathrm{ab}}$ & $327.2 \pm 36.8^{\mathrm{a}}$ & $316.2 \pm 63.9^{\mathrm{a}}$ & $170.74 \pm 32^{\mathrm{c}}$ \\
Flocculation (\%) & $93.8 \pm 0.40^{\mathrm{a}}$ & $93.4 \pm 0.17^{\mathrm{a}}$ & $92.9 \pm 0.13^{\mathrm{a}}$ & $92.71 \pm 0.16^{\mathrm{a}}$ \\
COD removal (\%) & $54.0 \pm 1.67^{\mathrm{b}}$ & $53.7 \pm 3.47^{\mathrm{b}}$ & $63.5 \pm 1.12^{\mathrm{a}}$ & $61.4 \pm 4.18^{\mathrm{a}}$ \\
Glycerol removal (\%) & $90.8 \pm 0.88^{\mathrm{a}}$ & $85.1 \pm 0.66^{\mathrm{b}}$ & $83.9 \pm 0.79^{\mathrm{b}}$ & $77.9 \pm 0.85^{\mathrm{c}}$ \\
Oil removal (\%) & $48.3 \pm 12.49^{\mathrm{c}}$ & $55.5 \pm 4.14^{\mathrm{b}}$ & $55.8 \pm 7.57^{\mathrm{b}}$ & $68.1 \pm 5.60^{\mathrm{a}}$ \\
\hline
\end{tabular}

Data are means with standard deviation.

Different superscript letters indicate significant differences between treatments. 
Table 2 Fatty acid composition (\%) of lipids extracted from different cycles of successivebatch fermentation

\begin{tabular}{lcccccccccccc}
\hline Conditions & C16:0 & C16:1 & C18:0 & C18:1 & C18:2 & C20:0 & C20:1 & C22:1 & C24:0 & Others & USFA & SFA \\
\hline Sterile effluent & & & & & & & & & & & & \\
\hline $1^{\text {st }}$ cycle & 38.90 & - & 7.10 & 43.15 & 7.81 & - & 0.93 & - & 0.39 & 1.73 & 51.89 & 48.12 \\
$2^{\text {nd }}$ cycle & 41.34 & - & 6.87 & 42.39 & 6.97 & - & - & 1.69 & - & 0.74 & 51.05 & 48.95 \\
$3^{\text {rd }}$ cycle & 35.61 & - & 6.74 & 44.82 & 9.47 & - & - & 1.72 & 0.35 & 1.28 & 56.01 & 43.98 \\
$4^{\text {th }}$ cycle & 42.12 & - & 7.14 & 41.81 & 5.50 & - & 1.45 & - & 0.21 & 1.77 & 48.76 & 51.24 \\
$5^{\text {th }}$ cycle & 37.35 & - & 6.65 & 43.61 & 7.79 & - & 0.80 & 2.54 & - & 1.26 & 53.94 & 46.06 \\
\hline Non-sterile effluent & & & & & & & & & & & \\
\hline $1^{\text {st }}$ cycle & 36.88 & 2.62 & 6.09 & 40.62 & 8.58 & 0.71 & - & 2.39 & 0.41 & 1.71 & 54.21 & 45.80 \\
$2^{\text {nd }}$ cycle & 38.55 & - & 6.71 & 42.79 & 7.99 & 1.03 & - & 1.22 & 0.36 & 1.37 & 52.00 & 48.02 \\
$3^{\text {rd }}$ cycle & 35.22 & - & 6.80 & 45.86 & 10.02 & - & - & 1.08 & - & 1.02 & 56.96 & 43.04 \\
$4^{\text {th }}$ cycle & 35.19 & - & 6.64 & 46.19 & 7.90 & 0.99 & - & 1.37 & 0.31 & 1.43 & 55.46 & 44.56 \\
$5^{\text {th }}$ cycle & 34.48 & - & 6.30 & 46.43 & 9.68 & 0.58 & - & 1.17 & 0.25 & 1.10 & 57.28 & 42.71 \\
\hline
\end{tabular}


Table 3 Biomass and lipid content of various yeasts cultivated in sterile and non-sterile systems

\begin{tabular}{|c|c|c|c|c|}
\hline Strains & Culture medium & $\begin{array}{c}\text { Biomass } \\
(\mathrm{g} / \mathrm{L})\end{array}$ & $\begin{array}{c}\text { Lipid } \\
\text { content }(\%)\end{array}$ & References \\
\hline \multirow{3}{*}{$\begin{array}{l}\text { Candida curvatus } \\
\text { ATCC } 20509\end{array}$} & Sterile municipal & 0.58 & 11.1 & Chi et al. (2011) \\
\hline & wastewater & & & \\
\hline & $\begin{array}{l}\text { Non-sterile municipal } \\
\text { wastewater }\end{array}$ & 0.51 & 9.1 & \\
\hline \multirow{3}{*}{$\begin{array}{l}\text { Rhodotorula glutinis } \\
\text { ATCC } 204091\end{array}$} & Sterile municipal & 0.40 & 6.2 & Chi et al. (2011) \\
\hline & wastewater & & & \\
\hline & $\begin{array}{l}\text { Non-sterile municipal } \\
\text { wastewater }\end{array}$ & 0.40 & 6.3 & \\
\hline \multirow{3}{*}{$\begin{array}{l}\text { Yarrowia lipolytica } \\
\text { ATCC } 20460\end{array}$} & Sterile municipal & 0.25 & 11.5 & Chi et al. (2011) \\
\hline & wastewater & & & \\
\hline & $\begin{array}{l}\text { Non-sterile municipal } \\
\text { wastewater }\end{array}$ & 0.23 & 6.6 & \\
\hline Metschnikowia & Sterile glycerol & 7.4 & 40 & Santamauro et al. (2014) \\
\hline pulcherrima & Non-sterile glycerol & 2.06 & 34 & \\
\hline Yarrowia lipolytica & Sterile effluent & 3.56 & 62 & This study \\
\hline TISTR 5151 & Non-sterile effluent & 6.90 & 53 & \\
\hline
\end{tabular}

This article is protected by copyright. All rights reserved. 